\title{
NICARAGUA EN CRISIS. AGUILAR ANTUNES, A., VILLACORTA, C. E. Y DE GORI, E. (COMPS.). BUENOS AIRES: SANS SOLEIL, 2018
}

Luis Serra Vázquez

Recibido: 02/05/2019 - Aceptado: 18/05/2019

Este libro presenta una compilación de 20 artículos de distintos autores sobre la crisis desatada en Nicaragua en abril 2018, al surgir un movimiento de protesta contra el régimen político liderado por Daniel Ortega desde el año 2007. Esta publicación trata de contribuir a la comprensión de esta crisis recogiendo distintas perspectivas de cientistas sociales latinoamericanos. La iniciativa surgió del Grupo de Trabajo de CLACSO "El istmo centroamericano: repensando los centros" donde participan los compiladores Aleksander Aguilar, Carmen Villacorta y Esteban De Gori.

En la introducción, Carmen Villacorta plantea que la situación de Nicaragua debe ubicarse dentro de las tres vertientes que presenta la izquierda en América Latina. Por un lado, quienes apuestan al rol de los partidos políticos progresistas que acceden al poder por la vía electoral para transformar desde el estado la sociedad; por otro lado, están quienes sostienen que los movimientos sociales son los actores claves para efectuar un cambio radical con amplia participación ciudadana; y, por último, se encontraría un "liberalismo de izquierda" que enfatiza el respeto de derechos ciudadanos y la gobernabilidad democrática. El régimen de Ortega se ubicaría en la primera vertiente, mientras que la oposición de izquierda compartiría las otras dos opciones criticadas por la autora.

A fin de facilitar la lectura de esta reseña, hemos optado por ordenar la heterogénea colección de ensayos presentando, en primer lugar, los sucesos ocurridos en Nicaragua en 2018 y sus antecedentes; en segundo lugar, las interpretaciones sobre los factores determinantes de la crisis; y, por último, algunas conclusiones. En cada sección retomamos los planteamientos de los autores y hacemos nuestra valoración.

\section{¿Qué ocurrió en esa coyuntura?}

Entre los hechos que desencadenaron las protestas, los autores mencionan, primero, la propuesta gubernamental de regulación de las redes virtuales que constituían uno de los pocos espacios de libre expresión e información. Segundo, el retraso de las autoridades en atender el incendio ocurrido en la reserva de biosfera Indio Maíz, 
un territorio indígena rama invadido por colonos ante la pasividad de las autoridades. Tercero, el decreto de reforma de la seguridad social que incrementaba los aportes de trabajadores y empleadores al mismo tiempo que reducía la pensión a los jubilados.

Esta reforma inconsulta fue rechazada por los gremios empresariales, trabajadores y jubilados. Al día siguiente, adultos mayores salieron a protestar en Managua, León y otras ciudades; estos fueron reprimidos por grupos de la Juventud Sandinista frente a una Policía Nacional pasiva. Las imágenes de esta agresión contra adultos mayores despertó la indignación popular y en varias ciudades los jóvenes salieron en su defensa.

Como señala Rueda:

Las protestas se intensificaron tras el uso de armas en contra de los manifestantes afuera de la Universidad Centroamericana (UCA), la Universidad de Ingeniería (UNI), la Universidad Politécnica (UPOLI) y la Catedral metropolitana... Los jóvenes organizados por medio de redes sociales se nombraron a sí mismos "los Auto convocados", para evitar ser identificados como miembros de algún partido político (97).

Por su parte, Miller plantea que "la Universidad Nacional Autónoma de Nicaragua (UNAM) se sumó para defender su autonomía universitaria, largamente secuestrada por dirigentes políticos ubicados en la Unión Nacional de Estudiantes de Nicaragua (UNEN)" (299). El intento de la UNEN por movilizar a los becarios de UNAM en contra de los protestantes agudizó el repudio estudiantil.

El liderazgo de Ortega-Murillo sufrió un quiebre drástico en esa coyuntura, así lo planteó De Gori: "El rechazo al intento de la modificación del sistema de seguridad social produjo que un sector de los adherentes se "retiraran" de ese vínculo que supone el liderazgo" (76).

En esta crisis, Castro destaca:

La fuerte incidencia de las comunicaciones, del Internet y las redes sociales, en particular, en la configuración del espacio político y la opinión pública...La situación sobrepasó las vías tradicionales de comunicación utilizadas por el gobierno, desactualizado en el manejo de las redes y (con) un enfoque de la centralización de la información (169).

Hay que señalar que el rol de las redes sociales vía internet se magnificó al suspender el gobierno los medios de comunicación independientes. También ocurrieron abusos tales como la divulgación de información e imágenes falsas, como plantean Castro y Fernández en sus artículos.

Las marchas de protesta surgieron rápidamente en muchas ciudades con una participación masiva de personas, al mismo tiempo que se levantaron tranques con adoquines en carreteras y barrios para evitar la penetración de fuerzas policiales, lo cual paralizó el transporte. Hubo incendios en edificios públicos, radios, viviendas, 
así como saqueo de negocios y ocupación de fincas propiedad de empresarios críticos del gobierno. La Asamblea Nacional retiró la personería jurídica a distintas ONG de derechos humanos y medios de comunicación y la policía confiscó sus bienes. Como señala E. Cuadra, una característica de este movimiento de protesta fue "la intensidad, extensión, diversidad y rapidez con la que escalaron las acciones sociales. El gobierno respondió con altos niveles de violencia y represión" (265).

Un rasgo interesante de la protesta que señalan varios autores es la utilización de un repertorio de medios que históricamente usó el Frente Sandinista de Liberación Nacional (FSLN) en su lucha contra la dictadura de Somoza, tales como marchas, barricadas, tranques, morteros, consignas, canciones y medios comunicación alternativos. Entre las consignas históricas se escuchaba en las marchas: “El pueblo unido jamás será vencido", "Sólo el pueblo salva al pueblo" y canciones como "Que vivan los estudiantes" (V. Parra) y "Nicaragua Nicaragüita” (C. Mejía). También surgieron nuevas consignas como "Ortega y Somoza son la misma cosa", "No eran delincuentes, eran estudiantes", "Patria libre y vivir", "Que se van, se van".

Las similitudes entre el régimen de Somoza y el actual de Ortega fueron analizadas en dos artículos de esta compilación. Salgado señala la ruptura del régimen con élites empresariales, el rol activo de estudiantes ajenos a partidos tradicionales, la perdida legitimidad y la condena internacional. Por su parte, De Gori considera que ambos fueron regímenes patrimonialistas que clausuraron la competencia política y ubicaron a familiares en el gobierno, recuerda que "Ambos líderes modificaron constituciones y ampliaron sus emprendimientos empresariales desde el Estado" (De Gori 79).

Al mes de iniciadas las protestas (16 de mayo del 2018) se abrió una mesa de diálogo con la mediación de la Conferencia Episcopal, la participación de representantes del gobierno y de la Alianza Cívica por la Justicia y la Democracia. El gobierno accedió a invitar a la Comisión Interamericana de Derechos Humanos (CIDH) a conocer la situación del país. Luego de una semana de investigaciones, la CIDH reportó haber documentado "graves violaciones de derechos humanos durante un mes de protestas, caracterizadas por el uso excesivo de la fuerza por parte de cuerpos de seguridad del Estado y de terceros armados". El informe identificó 76 personas muertas, 868 heridas, 438 detenidas y planteó 15 recomendaciones, básicamente el cese de la represión, el respeto de los derechos ciudadanos y la investigación de las muertes ocurridas (Comisión Interamericana de Derechos Humanos 2018a).

Estas propuestas de la CIDH fueron aceptadas por ambas partes en el diálogo, pero no fueron cumplidas por el gobierno. En su tercera y última sesión (26 de mayo del 2018), la propuesta de la Alianza por la democratización del país fue calificada por el gobierno de intento de golpe de Estado, al mismo tiempo que demandaba el levantamiento de los tranques. El diálogo se suspendió, el gobierno aprobó una ley antiterrorista para judicializar a los protestantes y lanzó una ofensiva militar para levantar los tranques en todo el país llamada “Operación Limpieza”. 
Como señala Aguilar en este operativo:

Miembros de la policía antidisturbios, elementos armados progubernamentales y turbas desmantelaron por la fuerza los tranques y barricadas. Esto dio lugar a enfrentamientos con los manifestantes, escalando el nivel de violencia en ambos lados (154).

La cantidad de asesinatos continuó en ascenso, al 19 de junio la CIDH reportó 212 muertos y 1337 heridos (Comisión Interamericana de Derechos Humanos 2018b). A fines de agosto, se contabilizaban 322 muertos y más de 2000 heridos, según el Informe del Comisionado de las Naciones Unidas para los Derechos Humanos (2018).

Observando en retrospectiva los sucesos ocurridos en 2018, a partir de los distintos artículos del libro se pueden distinguir cuatro fases: Un primer mes de rápida expansión de las protestas y los tranques frente a una respuesta represiva. Una segunda etapa donde se intentó un diálogo y negociación entre las partes en conflicto. Una tercera etapa caracterizada por el cierre del diálogo y la ofensiva militar contra el movimiento de protesta. En la cuarta etapa se observa una represión selectiva de líderes y participantes en las protestas que fueron criminalizados por terrorismo, lo cual provocó una emigración masiva del país.

En la presentación de los hechos ocurridos en esta coyuntura, se observa en esta compilación una diferencia clara entre los autores que comparten el discurso gubernamental y quienes retoman los datos presentados en los informes de organismos de derechos humanos. Los primeros destacan los actos de violencia supuestamente cometidos por grupos de protestantes y desconocen las agresiones cometidas por la policía y grupos afines. Mientras que, por su parte, la mayoría de los autores asumen los resultados de las investigaciones realizadas por distintas instituciones nacionales e internacionales de derechos humanos, que ha sintetizado el informe elaborado por el Grupo Interdisciplinario de Expertos Independientes (GIEI):

El GIEI pudo comprobar que el Estado recurrió al uso abusivo e indiscriminado de la fuerza para reprimir manifestaciones pacificas de protesta... la mayoría de los asesinatos y lesiones graves son responsabilidad de la Policía Nacional... desde las máximas autoridades del Estado se sostuvo un discurso público de estigmatización de las protestas y se exhibió un aval político a la represión... (180).

\section{¿Qué interpretaciones de la crisis presentan los autores?}

Todos los autores reconocen que el estallido de la crisis del 2018 es resultado de procesos y sucesos antecedentes que se sumaron a los hechos detonantes mencionados. Osorio, Cortez y Sánchez analizan "la coyuntura crítica actual de Nicaragua como resultado de la combinación de condiciones estructurales históricas y nuevas, 
y de las protestas sociales contingentes... intervienen estructuras de poder y actores nacionales y globales (214).

Entre los factores estructurales los autores mencionan: un Estado autoritario con un régimen corporativista, una cultura política signada por el providencialismo y el pragmatismo, un modelo económico capitalista extractivista, una crisis del trabajo y la seguridad social. En este tema, el déficit del Instituto de Seguridad Social (INSS) que pretendía superar el decreto cuestionado, se debía al exceso de personal y gastos administrativos, así como a millonarios préstamos otorgados al estado y personeros del régimen, según estudio del FUNIDES (Osorio et al. 220).

Al igual que otros autores, Baldizón considera que la crisis es "el resultado de un descontento acumulando durante varios años, durante los cuales se impuso una política continua de represión a las protestas sociales" (162). El autor identifica un ciclo de violencia en la medida que el descontento social recibe una respuesta agresiva por parte del gobierno generando una escalada de violencia.

Igualmente, Sánchez plantea que:

La población nicaragüense en su vehemente aversión a la masacre estudiantil también liberó todas las tensiones acumuladas durante más de una década de subordinación. Así que las protestas se intensificaron de forma espontánea sumando viejas y nuevas demandas sociales de sectores heterogéneos (138).

En este sentido, Miller señala que:

La crisis es producto de un cumulo de malestares...la imposición de tres periodos consecutivos del Sr. Ortega en la presidencia por medio de componendas políticas y fraudes electorales... la concentración del poder político en la familia gobernante, la cooptación de los poderes del estado bajo la presidencia y el manejo del presupuesto nacional y la ayuda venezolana (298).

En varios artículos se menciona un listado de demandas y protestas sociales reprimidas a partir del 2007 cuando asumió Ortega el gobierno: movimiento de mujeres contra la penalización del aborto, obreros de mina El Limón por condiciones laborales justas, excombatientes sandinistas por indemnización, adultos mayores por pensión reducida, campesinos e indígenas en defensa de sus tierras amenazadas por el canal, pobladores de Santo Domingo afectados por empresa minera, habitantes del municipio Rancho Grande opuestos a concesión minera, comunidades indígenas del Caribe invadidas por colonos, además de los reclamos de partidos políticos por fraudes electorales en 2008, 2011 y 2015.

Como señala Rueda: 
Las plazas, las calles, las rotondas y los monumentos se convirtieron en lugares de reunión de uso exclusivo para el gobierno-partido y sus aliados. Prácticamente cualquier manifestación contraria al Danielismo era duramente reprimida, acordonada o escoltada por efectivos policiales (102).

Por su parte, Aguilar plantea que "La lucha anti canal es el verdadero antecedente de la presente sublevación nicaragüense" (158). El autor estuvo en Bluefields en enero 2018 y fue asediado por investigar la situación de las comunidades indígenas afectadas por ese proyecto que otorgaba una concesión de $3423.9 \mathrm{~km}^{2}$ donde viven 119 200 personas a una empresa china por 100 años.

En su artículo, Cuadra expone cuáles han sido los mecanismos utilizados por el régimen de Ortega para enfrentar las protestas: por un lado, el aparato de coerción integrado por la Policía Nacional, la Dirección de Migración y los grupos paramilitares; y, por otro lado, los dispositivos de control social formados en barrios y entes estatales por los Comités de Liderazgo Sandinista y Gabinetes de Familia (266).

Fernández considera que hay dos visiones opuestas sobre la crisis:

Una sostiene que el pueblo nicaragüense, cansado de la opresión de un gobierno dictatorial, decidió levantarse y enfrentarse desarmado, contra las fuerzas policiales y grupos de civiles armados que le reprimen brutalmente. La otra, asegura que el gobierno enfrenta un plan macabro de desestabilización, organizado y dirigido por fuerzas oscuras encubiertas como organismos no gubernamentales (189).

Este planteamiento simplifica, en una visión dicotómica, una diversidad de interpretaciones que encontramos en esta compilación y en otros estudios sobre la crisis. En todo caso, estas visiones pueden considerarse como hipótesis cuya validez descansa en los hechos comprobados empíricamente.

La autoría del gobierno norteamericano en las protestas es planteada por Guillermo Pérez, quien considera que sus intereses geopolíticos fueron afectados por varias razones: la concesión del canal a una empresa china, las inversiones militares rusas, la alianza con el gobierno de Venezuela y el acercamiento a Irán (257). La política exterior de Ortega ha replicado la situación de la década de 1980, como plantea González: "la estrategia de vinculación externa manifiesta desde Managua se basa aún en la lógica Este-Oeste, con las características de una cruzada internacional contra enemigos de décadas pasadas... Con una fuerte retórica anti-imperialista" (205).

Midence y Ayerdis retoman el discurso gubernamental que considera la protesta popular como fruto de un plan orquestado por el imperialismo norteamericano apoyado en grupos de oposición con el objetivo de derrocar al gobierno. Esta versión de un supuesto golpe de Estado ha sido descartada por diversos actores nacionales e internacionales por carecer de evidencias probatorias. 
El discurso oficial que replican estos autores opera una inversión ideológica de la realidad para justificar las acciones represivas del régimen: el movimiento de protesta estaría conformado por terroristas que han asesinado gente, destruido propiedades, saqueado empresas y casas y manipulado los medios de comunicación y las redes sociales. Contrariamente, el gobierno actuaría basado en valores cristianos de solidaridad, paz, amor y reconciliación. Este discurso se transmite diariamente a través de los medios oficialistas que predominan en el país configurando una realidad virtual que termina siendo creíble para algunas personas, particularmente quienes viven en otros países incluyendo grupos de "izquierda" que creen que el FSLN es el mismo de la década de 1980.

La evolución del FSLN en la década de 1990 es analizada por Humberto Meza, quien señala la centralización del poder en D. Ortega, lo cual provocó la división del partido y su conversión en un partido electorero (90-91). Así ha surgido la diferenciación entre orteguismo y sandinismo, como plantea Sánchez:

El orteguismo alude a un pragmatismo politico que mezcla religiosidad popular, conservadurismo, esoterismo, corporativismo, caudillismo y fanatismo con un discurso de izquierda como velo para ocultar una praxis política y económica neoliberal (Sánchez 134).

\section{Conclusiones}

Este libro constituye un valioso aporte para la comprensión de la compleja crisis que vive Nicaragua desde abril 2018, a partir de las distintas perspectivas que presentan sus autores. Sin duda, la rapidez de su confección y la dinámica de un proceso en curso plantean un reto para el análisis a profundidad de esta problemática.

La compilación presenta artículos de distinta calidad y fundamentación; predominan los ensayos cortos de carácter descriptivo con una limitada base teórica, entre los cuales destacan los trabajos de Esteban de Gori sobre el liderazgo y la cultura política, así como el análisis estructural de esta coyuntura crítica por Osorio, Cortes y Sánchez.

La introducción de C. Villacorta pretende otorgar igual validez a la narrativa progubernamental que a la visión crítica del régimen político; sin embargo, la primera carece de pruebas fehacientes, contrariamente a los reportes de organismos internacionales (CIDH, MESENI y GIEI) basados en cientos de testimonios y fuentes audiovisuales, los cuales la autora ignora suponiendo que Nicaragua vive un proceso revolucionario.

El artículo de Villacorta concuerda con la posición de representantes de CLACSO, quienes interpretan la crisis nicaragüense en términos geopolíticos de una contradicción entre imperialismo-revolución y que respaldan a los "gobiernos progresistas" de una supuesta izquierda que desea perpetuarse en el poder sin respetar los derechos humanos y las normas mínimas de democracia electoral. 
Por el contrario, la Asociación Centroamericana de Sociología, con un conocimiento cercano de esta realidad y una posición ética y política clara ha señalado: “Nuestra irrestricta solidaridad con los/las estudiantes y con el pueblo de Nicaragua, porque su lucha y movilización es reconocida como ciudadanía que protesta en defensa de sus derechos" (15 de julio de 2018).

\section{Bibliografía}

Aguilar Antunes, A. Del Canal al Espejo: ¿quién es el pueblo en Nicaragua? Nicaragua en crisis. Comps. A. Aguilar Antunes, C. E. Villacorta y E. De Gori. Buenos Aires: Sans Soleil, 2018. 143-160.

Aguilar Antunes, A., Villacorta, C. E. y De Gori, E. (Comps.). Nicaragua en crisis. Buenos Aires: Sans Soleil, 2018. Recuperado de https://ddrn.dk/wp-content/uploads/2019/04/ nicaragua_en_crisis.pdf

Ayerdis, M. Tópicos, manipulaciones e impunidad en el discurso justificador del fallido golpe de estado del 18 abril en Nicaragua. Nicaragua en crisis. Comps. A. Aguilar Antunes, C. E. Villacorta y E. De Gori. Buenos Aires: Sans Soleil, 2018. 53-72.

Baldizón, A. La razón de la represión. Nicaragua en crisis. Comps. A. Aguilar Antunes, C. E. Villacorta y E. De Gori. Buenos Aires: Sans Soleil, 2018. 161-168.

Castro, I. Nicaragua: comunicación y redes en la crisis. Nicaragua en crisis. Comps. A. Aguilar Antunes, C. E. Villacorta y E. De Gori. Buenos Aires: Sans Soleil, 2018. 169-188.

Comisión Interamericana de Derechos Humanos. "Graves violaciones a los derechos humanos en el marco de las protestas sociales en Nicaragua". 2018b. Recuperado de http:// www.oas.org/es/cidh/informes/pdfs/Nicaragua2018-es.pdf

Comisión Interamericana de Derechos Humanos. Observaciones preliminares de la visita de trabajo de la CIDH a Nicaragua. 2018a. Recuperado de https://www.oas.org/es/cidh/ prensa/comunicados/2018/113.asp

Cuadra, E. Dispositivos del silencio: control social y represión en Nicaragua. Nicaragua en crisis. Comps. A. Aguilar Antunes, C. E. Villacorta y E. De Gori. Buenos Aires: Sans Soleil, 2018. 265-277.

De Gori, E. Abril 18. Los meses que conmocionaron a un liderazgo. Nicaragua en crisis. Comps. A. Aguilar Antunes, C. E. Villacorta y E. De Gori. Buenos Aires: Sans Soleil, 2018. 73-88.

De Gori, E. Una crisis insospechada y la convulsión de un orden. Entrevista a Salvador Martí i Puig. Nicaragua en crisis. Comps. A. Aguilar Antunes, C. E. Villacorta y E. De Gori. Buenos Aires: Sans Soleil, 2018. 260- 263.

Equipo IEEPP. La criminalización de la protesta social en el gobierno de Ortega-Murillo. Comps. A. Aguilar Antunes, C. E. Villacorta y E. De Gori. Buenos Aires: Sans Soleil, 2018. 284-295.

Ester Bárbara y González Guillermo. Nicaragua: de la revolución al feminicidio de Estado. Nicaragua en crisis. Comps. A. Aguilar Antunes, C. E. Villacorta y E. De Gori. Buenos Aires: Sans Soleil, 2018. 278-283.

Fernández, G. Algunos elementos para comprender mejor lo que ocurre en Nicaragua. Nicaragua en crisis. Comps. A. Aguilar Antunes, C. E. Villacorta y E. De Gori. Buenos Aires: Sans Soleil, 2018. 189-204. 
González, T. La política exterior de Daniel Ortega. Las relaciones internacionales de Nicaragua desde 2006. Nicaragua en crisis. Comps. A. Aguilar Antunes, C. E. Villacorta y E. De Gori. Buenos Aires: Sans Soleil, 2018. 205-210.

Grupo Interdisciplinario de Expertos Independientes. Informe sobre los hechos de violencia ocurridos entre el 18 de abril y el 30 de mayo de 2018. Recuperado de https://gieinicaragua.org/giei-content/uploads/2019/02/GIEI_INFORME_DIGITAL_07_02_2019_VF.pdf

Meza, H. Sandinismo sin Ortega u Orteguismo sin Sandino: La encrucijada actual. Nicaragua en crisis. Comps. A. Aguilar Antunes, C. E. Villacorta y E. De Gori. Buenos Aires: Sans Soleil, 2018. 89-95.

Midence, C. El Sandinismo frente al fallido golpe de estado y sus correlatos. Nicaragua en crisis. Comps. A. Aguilar Antunes, C. E. Villacorta y E. De Gori. Buenos Aires: Sans Soleil, 2018. 28-52.

Miller, D. "Nicaragua ante un cambio social inminente. Una lectura desde la Costa Caribe".

Oficina del Alto Comisionado de las Naciones Unidas para los Derechos Humanos. Violaciones a los derechos humanos y abusos en el contexto de las protestas en Nicaragua 18 abril-18 agosto 2018. Ginebra. Recuperado de https://www.ohchr.org/Documents/ Countries/NI/HumanRightsViolationsNicaraguaApr_Aug2018_SP.pdf

Osorio, H., Cortez, A. y Sánchez M. Coyuntura crítica en Nicaragua: orígenes estructurales y posibles giros de cambio. Nicaragua en crisis. Comps. A. Aguilar Antunes, C. E. Villacorta y E. De Gori. Buenos Aires: Sans Soleil, 2018. 211-253.

Pérez, G. Nicaragua: una guía para comprender una crisis desde sus rasgos estructurales y geopolíticos. Nicaragua en crisis. Comps. A. Aguilar Antunes, C. E. Villacorta y E. De Gori. Buenos Aires: Sans Soleil, 2018. 254-259.

Rueda, V. Que se rinda tu madre. Los nuevos/viejos símbolos y tácticas de la movilización social en Nicaragua. Nicaragua en crisis. Comps. A. Aguilar Antunes, C. E. Villacorta y E. De Gori. Buenos Aires: Sans Soleil, 2018. 96-126.

Salgado, M. M. Patria libre y vivir. Nicaragua en crisis. Comps. A. Aguilar Antunes, C. E. Villacorta y E. De Gori. Buenos Aires: Sans Soleil, 2018. 127-132.

Sánchez, D. A. Protesta social en Nicaragua: ¿derecho o delito? Nicaragua en crisis. Comps. A. Aguilar Antunes, C. E. Villacorta y E. De Gori. Buenos Aires: Sans Soleil, 2018. 133-142. Villacorta, C. E. Nicaragua en 2018. Notas sobre un libro incómodo. Nicaragua en crisis. Comps. A. Aguilar Antunes, C. E. Villacorta y E. De Gori. Buenos Aires: Sans Soleil, 2018. 8-26.

Luis Serra Vázquez. Nicaragüense. Profesor de Sociología en la Universidad Centroamericana de Managua y miembro de la Fundación Entre Volcanes una ONG de desarrollo local en Ometepec. Es Licenciado en Historia por la Universidad Nacional de Buenos Aires (Argentina), Master en Ciencias Políticas por la Universidad de Ohio (USA) y Doctor en Sociología por la Universidad de Lovaina (Bélgica).

Contacto: luishectorserra@yahoo.com.ar

ORCID: 0000-0001-7038-8301 
